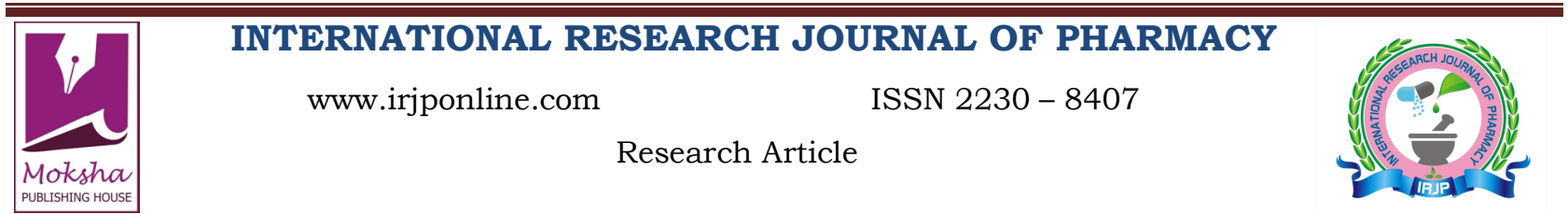

\section{EVALUATION OF SUBACUTE ANTIDEPRESSANT ACTIVITY OF ALOCASIA MACRORRHIZOS ON MICE}

Kateel Ramya*, Rai Mohandas, Alva Akshaya, Aravind Aiswarya, Prajwal Pooja

Department of Pharmacology, A.J. Institute of Medical Sciences, Mangalore, India

*Corresponding Author Email: ramyakateeel@hotmail.com

Article Received on: 13/03/13 Revised on: 06/04/13 Approved for publication: 07/05/13

DOI: 10.7897/2230-8407.04626

IRJP is an official publication of Moksha Publishing House. Website: www.mokshaph.com

(c) All rights reserved.

\begin{abstract}
The increased prevalence of depression at $12.3 \%$ rate and side effect profile of the existing antidepressants led to the present study which was designed to establish the role of natural herbal medicine Alocasia macrorrhizos as an antidepressant and to extend these results before the safe application in humans. 48 Albino male mice were divided into 2 sets each consisting of 4 groups with 6 animals in each group. Groupland 2 served as control and standard where as group3 and 4 were treated with hydroalcoholic extract of Alocasia macrorrhizos at the dose of $250 \mathrm{mg} / \mathrm{kg}$ and $500 \mathrm{mg} / \mathrm{kg}$ respectively. Drugs were suspended in $1 \%$ gumacasia and administered to mice orally one hour before test procedure. Forced swim test and tail suspension tests were standard animal models used for assessing antidepressant activity by recording the immobility time. Results from the study showed that hydroalcoholic extract of Alocasia macrorrhizos had significantly reduced immobility duration at the dose of $250 \mathrm{mg} / \mathrm{kg}$ and $500 \mathrm{mg} / \mathrm{kg}$ where it has shown better result than control group when subjected to the test procedures. Significant difference in immobility duration were noticed when these groups were compared to standard imipramine and there was a definite antidepressant effect observed with AM $500 \mathrm{mg} / \mathrm{kg}$ whereas AM $250 \mathrm{mg} / \mathrm{kg}$ values were comparable to imipramine. Hence we have concluded from the results of the study that hydroalcoholic extract of leaves of Alocasia macrorrhizos has the definite antidepressant effect which is comparable to Imipramine at $250 \mathrm{mg} / \mathrm{kg}$ dose.
\end{abstract}

Keywords: Alocasia macrorrhizos, FST, immobility time, TST, imipramine

\section{INTRODUCTION}

Depression is considered as an affective disorder characterized by change in mood, lack of interest in the surroundings, psychomotor retardation and melancholia. It is often a disabling disease that affects a person's work, family, school life, sleeping and eating habits.

General health and ability to enjoy life. ${ }^{1}$ Patients with major depression have symptoms that reflect changes in brain monoamine-transmitters specifically norepinephrine, serotonin and dopamine ${ }^{2}$. According to world health report, about 450 million people suffer from a mental or behavioral disorder. This amounts to $12.3 \%$ of the global burden of disease, and predicted to rise up to $15 \%$ by $2020 .^{2}$ despite the advent of new molecules in the pharmacotherapy of depression; it is unfortunate that this disorder still goes undiagnosed and untreated. Although the currently prescribed molecules provide some improvement in the clinical condition of the patient, it is at the cost of having to bear the burden of their adverse effects ${ }^{3}$. The use of alternate medicines is increasing worldwide day by day in various diseases. Hence, finding newer and safer therapeutic agents would benefit the existing treatment modalities.

Alocasia macrorrhizos is an indigenous herb belonging to the family Araceae. They are naturally grown on marshy land of tropical area in India. Bangladesh, China. Different parts of this plant are traditionally used in inflammation ${ }^{4}$. The juice of leaves of the plant is used as a digestive, laxative, diuretic, astringent, antifungal agent and for the treatment of rheumatoid arthritis. The leaves of this plant are used to prevent iron deficiency, to enhance eye sight and as a good source of protein. Also the whole plant is used for jaundice and constipation ${ }^{5}$. Leaf extract of Alocasia macrorrhizos is proven to have anti oxidant ${ }^{6}$, antinociceptive, antiinflamattory ${ }^{7}$, laxative, $\operatorname{diuretic}^{8}$ and hepatoprotective ${ }^{9}$ properties. Rhizome extract has shown antihyperglycemic, antioxidant and cytotoxic activity in various studies ${ }^{10}$. Since increased oxidative stress occurs in major depression, as evidenced by defective plasma antioxidant defenses in conjunction with enhanced lipid peroxidation, treating depression with antioxidant has emerged as a newer modality for treatment of depression ${ }^{11-13}$. Leaf extract of Alocasia macrorrhizos is proven to have anti oxidant property. But literature search revealed that antidepressant property of Alocasia macrorrhizos is not yet studied in any of the models. Based on above data we hypothesized that this plant may have antidepressant property and hence this study was undertaken to evaluate the antidepressant property of hydroalcoholic extract of leaves of Alocasia macrorrhizoson mice.

\section{MATERIALS AND METHODS}

\section{Plant material}

Fresh leaves of Alocasia macrorrhizos (Araceae) collected from different places at Mangalore were identified and authenticated by Dr. Gopalakrishna Bhat, Department of Botany, Poornaprajna College, Udupi and a voucher specimen was deposited at the Herbarium of institute.

\section{Preparation of Extracts (by cold maceration method)}

Fresh leaves of Alocasia macrorrhizos were shade dried for about ten days and homogenized to get a coarse powder. Powder (500gm) was extracted with ethanol (99\%) and distilled water in 1: 1 proportion at room temperature by cold maceration method. The filtrate was collected and concentrated on a heating mantle at $45^{\circ} \mathrm{C}$ till a syrupy consistency was obtained. The extract was successively dried by using a rotary evaporator and preserved at $<0^{\circ} \mathrm{C}$. The percentage yield of the extract was found to be $6.75 \%{ }^{13}$.

\section{Experimental Animals}

Swiss albino mice of either sex, inbred in the institutional animal house were used for the study. Mice were housed in clean polypropylene cages, six mice in each cage, in a controlled environment $\left(24-26^{\circ} \mathrm{C}\right)$ with a 12 hour light and 
dark cycle with standard chow containing fat $4.15 \%$, protein $22.15 \%$, carbohydrates $4 \%$. The mice were allowed to acclimatize to these conditions for one week. The experiment was performed during the light phase of the cycle (10:0017:00hours). The animals were maintained as per the CPCSEA guidelines and regulations. The study was approved by the Institutional animal ethics committee.

\section{Study procedure}

Mice were randomly assigned to 4 groups of 6 mice each. Grouping and treatment schedule for each group is as shown in Table 1. All the drugs were suspended in $1 \%$ gumacasia and given orally once daily for all the animals.

\section{Evaluation of antidepressant activity \\ Forced swim test}

Forced swim test apparatus consist of a vertical Plexiglas cylinder of height $50 \mathrm{~cm}$, diameter $20 \mathrm{~cm}$. Glass cylinder was filled with water (room temperature) of about $15 \mathrm{~cm}$ of height. Animals were prescreened on the previous day by placing them in the forced swim test apparatus. After 5-6min immobility reaches a plateau where the mice remained immobility for approximately $80 \%$ of the time. After $15 \mathrm{~min}$ in the water animals were removed and allowed to dry in a heated enclosure $\left(32^{\circ} \mathrm{c}\right)$ before being returned to their home cage. All the group animals were treated with their respective drugs for about 15 days. On $15^{\text {th }}$ day animals were screened for their antidepressant activity by placing them individually in glass beaker filled with $15 \mathrm{~cm}$ water for about six min. Total immobility duration was recorded during last four minutes. A mouse was considered immobile when it remained floating in the water without struggling, making only minimum movements of its limbs necessary to keep its head above water. Water in the glass jar was changed every time after screening ${ }^{16}$.

\section{Tail suspension test}

Tail suspension test apparatus consist of metal rod stand of $50 \mathrm{~cm}$ height above the table top. Mice were suspended on the metal rod with the help of an adhesive tape placed approximately one $\mathrm{cm}$ from the tip of the tail. After 15days drug treatment mice were suspended in tail suspension test apparatus and duration of immobility was recorded for the duration of eight minutes. Animal was considered to be immobile when it did not show any movement of body and hanged passively Immobility duration during first two min was not taken in to account because of vigorous activity shown by animals. Immobility duration of test, control and standard groups was compared ${ }^{16}$.

\section{Statistical Analysis}

All results are expressed as Mean $\pm \mathrm{SE}$. All the groups will be analyzed using one way ANOVA followed by Dunnets multiple comparison test. Data was analyzed using SPSS Software version 17 . $\mathrm{P}<0.05$ was considered statistically significant.

Table 1: Drug treatment schedule

\begin{tabular}{|c|c|c|}
\hline & Group & Drug treatment \\
\hline Group I & Control & Gumacasia $10 \mathrm{ml} / \mathrm{kg} \mathrm{p.o}$ \\
\hline Group II & standard & Imipramine $15 \mathrm{mg} / \mathrm{kg} \mathrm{p.o}$ \\
\hline Group III & test 1 & Alocasia macrorrhizos (AM) hydroalcoholic extract $250 \mathrm{mg} / \mathrm{kg}^{6}$ \\
\hline Group IV & test II & Alocasia macrorrhizos (AM) hydroalcoholic extract $500 \mathrm{mg} / \mathrm{kg}^{6}$ \\
\hline
\end{tabular}

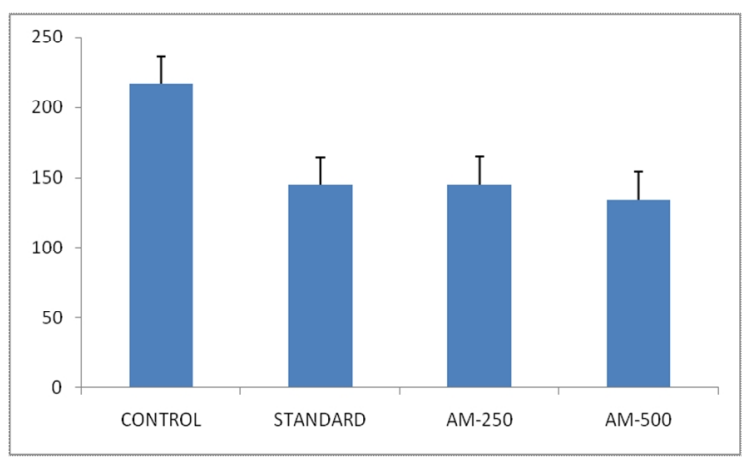

Graph I: Effect of Alocasia macrorrhizs on duration of immobility in forced swim test

Each histogram represents duration of immobility in seconds $(n=6)$. Vertical line on top represents standard error of mean.

When compared to control all three group values were significant $(\mathrm{p}<0001)$

\section{RESULTS}

As shown in Graph 1. In forced swim test control group animal showed immobility for duration of $94.80 \pm 8.974 \mathrm{~min}$ where as immobility duration of standard, AM-250, AM-500 group animas was $26.17 \pm 11.7 \mathrm{sec}, \quad 13.83 \pm 10.8 \mathrm{sec}$, $3.67 \pm 2.7 \mathrm{sec}$ respectively. When test and standard values were compared to control group there was a significance difference in immobility duration of both the groups. $(\mathrm{p}<0.001$ compared to control). But when immobility duration values were compared to standard drug there was no significant

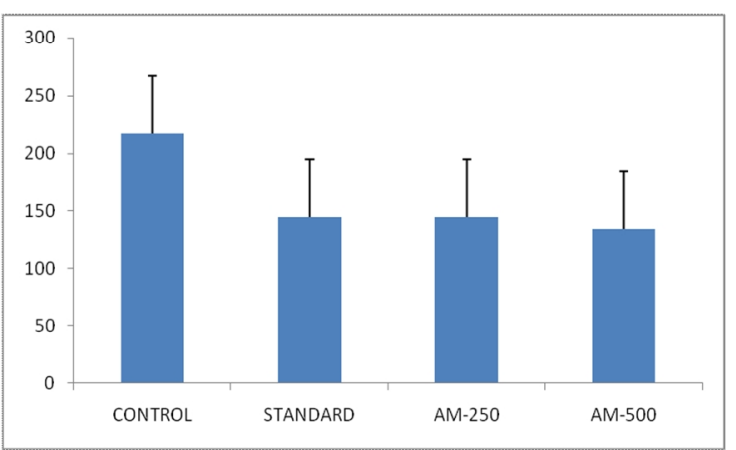

Graph II: Effect of Alocasia macrorrhizs on duration of immobility in tail suspension test

Each histogram represents duration of immobility in seconds $(n=6)$. Vertical line on top represents standard error of mean.

When compared to control all three group values were significant $(\mathrm{p}<0.001)$.

difference between standard and both the dose of test drug but these values were comparable. In tail suspension test as shown in graph 2 there was a significance difference $(\mathrm{p}<0.001)$ in duration of immobility of standard $(144.83 \pm 10.5 \mathrm{sec})$ and both the test groups $(145.33 \pm 7.5$ and $134.17 \pm 15.46 \mathrm{sec})$ when compared to control group $(216.50 \pm 6.02 \mathrm{sec})$. Whereas when immobility duration of both the dose of AM was compared to standard drug there was no significance difference between these groups but both the group values were comparable. 


\section{DISCUSSION}

In this study mice were treated with hydroalcoholic extract of Alocasia macrorrhizos at the dose of $250 \mathrm{mg} / \mathrm{kg}$ and $500 \mathrm{mg} / \mathrm{kg}$ for about 15 days once daily which was compared with control group which didn't receive any treatment except Gumacasia at the dose of $10 \mathrm{ml} / \mathrm{kg}$ and standard drug Imipramine which was given at the dose of $15 \mathrm{mg} / \mathrm{kg}$ for 15 days once daily to evaluate the antidepressant activity using two well established models i.e. forced swim test and tail suspension test. Forced swim test animal model is based on the principle that forcing mice to swim in restricted space from which they cannot escape leads to a characteristic behavior of immobility. This behavior reflects a state of despair, which can be reduced by several agents that are therapeutically effective in human depression. Whereas Tail suspension test is a variant of the behavioral despair test in which immobility is induced by simply suspending a mouse by tail. This test is reliable and rapid screening method for antidepressants, including those involving serotonergic system $^{16}$. Imipramine which was taken as standard drug in study is a monoamine reuptake inhibitor which is used for pharmacotherapy of depression. Imipramine treated animals showed a significant decrease in duration of immobility when compared to control group of animals proving its antidepressant activity in both the models. Animals which were treated with Alocasia macrorrhizos also showed antidepressant activity. There was significant difference in duration of immobility of AM treated rats at both the doses i.e. $250 \mathrm{mg} / \mathrm{kg}$ and $500 \mathrm{mg} / \mathrm{kg}$ when compared to control. But when compared to standard drug imipramine results were insignificant but both group values were comparable. Oxidative stress represents a loss of balance in oxidation reduction reaction. It is characterized by reduced ability of the antioxidant defense system to efficiently eliminate the excess of oxygen derived species production, eliciting the toxicity of oxygen and its detrimental effects. Increased oxidative stress is seen in patients suffering from depression $^{18}$. N-acetylcystiene has been tried as a newer modality for treatment of depression with encouraging results $^{19}$. Our test drug Alocasia macrorrhizos is recorded among cultivated medicinal as well as vegetable plants by the folklore of south Asia. This plant is proven to have many pharmacological actions including antioxidant properties ${ }^{6}$. Phytochemical screening of this plant has showed that it contains flavonoids, cynogenetic glycosides, ascorbic acid, gallic acid, mallic acid, oxalic acid, alocasin, amino acids, succinic acid and $\beta$-lectines ${ }^{17}$. Hence the antidepressant activity of Alocasia macrrhizos shown in our study may be because of its antioxidant property. These results support the earlier study which has shown acute antidepressant activity of Alocasia macrorrhizos ${ }^{20}$.

\section{CONCLUSION}

To conclude hydroalcoholic extract of Alocasia macrorrhizos has antidepressant property at the dose of $500 \mathrm{mg} / \mathrm{kg}$ and $250 \mathrm{mg} / \mathrm{kg}$ where it has shown significantly better result than control group and also antidepressant activity is comparable with standard antidepressant drug Imipramine. However, the exact mechanism(s) involved in these effects will have to be elucidated in future studies which may be because of antioxidant property or some other mechanism.

\section{REFERENCES}

1. Reynolds EH. Brain and mind: A challenge for WHO. Lancet Com 2003; 36: 1924- 1925. http://dx.doi.org/10.1016/S0140-6736(03)136008

2. The world health report: Mental Health: New understanding new hope. WHO, Geneva; 2001.

3. Shalam M, Shantakumar SM, Narasu ML. Pharmacological and biochemical evidence for the for the antidepressant effect of the herbal preparation trans-01. Indian J Pharmacol 2007; 39(5): 231-34. http:// dx.doi.org/10.4103/0253-7613.37273

4. Nadkarni KM, Basu BD. Alocasia indica in Indian Material Medica (Popular prakashan Ltd, Mumbai, India) 72.

5. Patil R Bhagyashree, Bamane H Sanjeevani, Khadsare R Ujwala. In vitro protection of hepatocytes by Alocasia macrorrhizos leaf juice against ccl4 and Tylenol Mediated hepatic injury. International Journal of Pharmaceutical Application 2011; 2(2): 122-27.

6. Mulla WA, Salunkhe VR, Kucherkar BS. Free radical scarving activity of leaves of Alocasia indica. Indian J Pharm Sci 2009; 71(3): 303-7. http://dx.doi.org/10.4103/0250-474X.56036PMid:20490298 PMCid:2865790

7. Mulla WA, Kuchekar SB, Thorat VS, Chopade AR, Kuchekar BS. Antioxidant, antinociceptive and anti-inflammatory activities of ethanolic extract of leaves of Alocasia indica (Schott.). J Young Pharm 2010; 2(2): 137-43. http://dx.doi.org/10.4103/0975-1483.63152 PMid:21264115 PMCid:3021687

8. Sheikh Mubeen, Misra Vimlesh, Banerjee Santanu. Laxative and diuretic activity of Alocasia macrorrhizos on experimental albino rats. International Research journal of Pharmacy 2012; 2(3): 172-74.

9. Mulla A Wahid, Salunkhe R Vijay, Bhishe B Satish. Hepatoprotective activity of hydroalcoholic extract of leaves of Alocasia indica. Indian $\mathrm{J}$ ExpBiol 2009; 47: 816-21. PMid:20112809

10. Md Masudurrahman, Md Aslamhossain, Saiful Alamsiddique. Antihyperglycemic, antioxidant and cytotoxic activities of Alocasia macrorrhizos (L.) Rhizome extract. Turk J Biol 2012; 3(6): 674-78.

11. Bilici $\mathrm{M}$ et al. Anti- oxidative enzyme activities and lipid peroxidation in major depression: Alteration by Depression treatment. Journal of Affective Disorder 2001; 64: 43 - 51. http://dx.doi.org/10.1016/S01650327(00)00199-3

12. Khanzode SD et al. Oxidative damage and major depression: the potential antioxidant action of selective serotonin re-uptake inhibitors. Redox Rep 2003; 8: 365-370. http://dx.doi.org/10.1179/135100003 225003393 PMid:14980069

13. Ozcan ME et al. Antioxidant enzyme activities and Oxidative stress in affective disorders. International Clinical Psychopharmacology 2004; 19:89-95.http://dx.doi.org/10.1097/00004850-200403000-00006 PMid: 15076017

14. Quality control methods for medicinal plants materials. Geneva: World Health Organisation; 1998. p. 32

15. Dhingra D, Sharma A. Evaluation of antidepressant like activity of glycyrrhizine in mice. Indian J Pharmacol 2005; 37(6): 390-4. http:// dx.doi.org/10.4103/0253-7613.19077

16. Vogel GH, Vogel WH. Drug discovery and evaluation-pharmacological assay. Springer Publication; 1997. p. 292-312 http://dx.doi.org/10.1007 /978-3-662-03333-3

17. Prajapati ND. A hand book of medicinal plants. India: Agrobois india; 2003. p. 32

18. Sarandol A, Sarandol E, Eker SS, Erinde S, Vatanserver E, Kirl S. Major depressive disorder is accompanied with oxidative stress: Short term antidepressant treatment does not alter oxidative - Antioxidative system. Humpsycophamrcol 2007; 22: 67-73.

19. Machado Vieira R, Salvadore G, Diazgrndson N, Ibrahim L, Latov D, Wheeler Castillo C et al. New therapeutic agent for treatment of mood disorders. Sci World J 2010; 10: 713-26. http://dx.doi.org/10.1100/t sw.2010.65 PMid:20419280 PMCid:3035047

20. Kateel ramya, Rai Mohandas, $P$ charishma, alva akshaya, prajwal pooja, aravind aishwarya. Antidepressant activity of Alocasia macrorrhizos on mice. American journal of pharmatech research. 2013; 3(3):676-83

Cite this article as:

Kateel Ramya, Rai Mohandas, Alva Akshaya, Aravind Aiswarya, Prajwal Pooja. Evaluation of subacute antidepressant activity of Alocasia macrorrhizos on mice. Int. Res. J. Pharm. 2013; 4(6):120-122 